a substitute for rubber in very hard articles, we may mention the interesting material, "bakelite," recently introduced by Dr. L. H. Baekeland. It is a condensation-product of formaldehyde and phenol, which can be moulded as desired, and afterwards hardened.

In what sense are the foregoing articles and their likes to be considered as "substitutes" for rubber? Some persons are disposed to deny them any right to the title, and would look upon them as mere adulterants whenever used partially to replace rubber in what would otherwise be an all-rubber article. Others admit, though sometimes grudgingly, that there is a place which such substitutes can usefully fill. Much depends on what the article is sold as, and on what use it is to be put to. Not all the special qualities of rubber are wanted in all the products for which it is employed. A door-mat is one thing, a bicycle tyre quite another. Where a high degree of elasticity is not really needed, as, for instance, in waterproof goods and electrical insulating work, there is a legitimate field for substitutes which may serve the required purpose. Even here they may not be equal to rubber, but they find their justification in their lower cost. After all, we do not need razors to cut sticks with.

It may be said at once that no substitute is equal to rubber in every respect. Chemically, the latter is a very inert substance-much more so than the substitutes. Hence, even if the latter were not otherwise inferior, they would be less durable than rubber under certain conditions. They are nearly all acted upon more or less readily in circumstances where rubber remains unharmed. The modified oils, in fact, are still oils in the sense that they remain glycerides, decomposable by alkalies, as also by steam under pressure. If used for articles exposed to these agencies, they fail in durability, whatever their excellences otherwise.

'The fact that substitutes of this class are readily saponifiable by alkali makes it an easy matter to detect them by analysis when compounded with true rubber. As a rule, the proportion of substitute used is from 5 to 25 per cent., and even the smaller quantity is recognisable.

Of the composite rubbers (or "artificial rubbers," as they are sometimes called), one preparation, which has been made in quantity, and is said to be excellent for many purposes, has for its basis Guayule rubber incorporated with certain gums. Another such article is compounded of natural rubber and some other substance of vegetable origin, probably a latex or a gum, reputed to contain the same chemical elements as rubber and in much the same proportion. Such articles are, of course, only partially "substitutes" for rubber, and their cost rises with that of the latter ingredient. Moreover, if any very large demand for them arose, there is always the possibility that the supply of gums and latices would become insufficient, and the advantage of lower cost would thus tend to disappear.

Coming now to true synthetic rubber; a question often asked is whether there exists any probability of such an article being manufactured and displacing natural rubber, either wholly or to any large extent. Will rubber plantations go the way of madder fields and indigo cultivation? Well, the future is on the knees of the gods. In the face of the precedents just mentioned, to say nothing of others, he would be a bold man who would venture to say that even the best quality of rubber may not some day be made on a commercial scale from cheaper materials such as beet sugar and calcium carbide. But the day is not yet. There are beginnings; there are clear indications of the direction in which to proceed; there is distinct

NO. 2107 , VOL. 83] progress to note. But there is still some distance to go, and the end of the journey may not be even in sight.

India-rubber chemically is essentially a polymerised terpene. An article patented some time ago, and named "turpentine rubber," appears to foreshadow a synthesis of true rubber. Turpentine is a mixture of terpenes, and the article in question was to be obtained by passing turpentine through a hot tube, and treating the resulting vapours with hydrochloric acid. The result is a solid condensation-product; and the idea at the base of the process appears to be the production of polymerised terpenes having some of the elastic properties of rubber.

A more promising, because a more scientific way, is that outlined in Heinemann's patent No. 21,772 of 1907. Here a true synthesis is attempted. It is based upon the well-known fact that rubber is probably a polymer of the semi-terpene isoprene. The first step is the production of the unsaturated hydrocarbon divinyl, $\mathrm{CH}_{2}$ : $\mathrm{CH} . \mathrm{CH}: \mathrm{CH}_{2}$. This is obtained by passing mixed acetylene and ethylene gases through a heated tube. With methyl chloride, divinyl yields isoprene [methyl divinyl, $\mathrm{CH}_{2}: \mathrm{C}\left(\mathrm{CH}_{3}\right) \cdot \mathrm{CH}: \mathrm{CH}_{2}$ ]; and the isoprene on treatment with strong hydrochloric acid is converted by a union of molecules into a substance closely resembling caoutchouc, if not identical with it. The raw materials, so to speak, are thus acetylene, ethylene, and methyl chloride, which are themselves obtained by any of the ordinary methods, e.g. from calcium carbide, alcohol, and beet sugar residues respectively.

The question is, can this or some other comparatively simple synthesis, theoretically quite possible as a laboratory operation, be translated into a practicable and profitable mode of manufacture on a large scale? One of the first doubts to arise is whether the synthesised caoutchouc will have the physical properties of natural rubber; or whether these, by any course of treatment, can be imparted to it. This doubt resolved, there comes the question of economical production in competition with the natural product. Much time and thought have been spent on the problem of synthetic rubber, and it is safe to conclude that there will yet bo many a headache before it is solved. Judging oy what is known to have been done rather than by the promises, owners of rubber plantations may for the present sleep peacefully in their beds.

C. Simmonds.

\section{REPORT OF THE ROYAL COMMISSION ON CANALS}

THE Royal Commission on Canals and Inland Navigation, the final report of which has recently been issued, was appointed in March, I006, and consisted of nineteen members, Lord Shuttleworth being chairman. Their instructions were to inquire into the present condition and financial position of the inland waterways of the United Kingdom; to report as to the causes which have operated to prevent the carrying out of improvements by private enterprise; as to improvements desirable in order to complete a through communication by water between the centres of commercial industry, and with the sea; the prospect of benefit to the trade of the country compatible with a reasonable return on the probable cost; the expediency of canals being acquired by public bodies; and the methods by which funds could be provided for their purchase and improvement.

Seven reports and returns have already been issued, and there are four more to follow, including that on the Irish waterways. 
The Commission held Io6 sittings, and examined 266 canal experts, traders, and rthers interested in the subject. They personally inspected the most important waterways in this country, and some of those in France, Belgium, Germany, and Holland, and obtained a report from an assistant commissioner on the inland waterways of the Continent.

The final report now issued covers 234 folio pages. It commences with an interesting history of British waterways, and then, seriatim, deals with the different questions submitted for consideration, and concludes with the recommendations at which the commissioners have arrived. These are not unanimous, the minority reports being also given.

Briefly, these recommendations are :-

The formation of a Central Waterway Board, and the transfer to this board of four central lines of canals connecting Birmingham, as the most central trading town of the Midland district, with London, Hull, Bristol,' and Liverpool.

If this waterway board, after further investigation, and if satisfied that with regard to general benefit to trade and financial considerations such a course is desirable, it should be empowered to enlarge and improve the existing waterways so as to afford through communication for barges, of roo tons, between the Midland district and the sea-ports.

The estimate given in the report for constructional works for these four waterways is $I 7 \frac{1}{2}$ millions, the money required for the purpose to be guaranteed by the State. The cost of maintenance, interest, and sinking fund is put at one million.

As already stated, the report is not unanimous. Five of the members sign it with certain reservations, and three members have given separate reports.

The reservations of the five members express their disagreement practically with all the recommendations, their agreement extending only to the historical part, the Scotch scheme, and certain minor matters.

The majority do not appear to have much faith in the scheme they recommend, as they only advise that it shall be carried out if the proposed waterway board is satisfied, after further inquiry, that this would be desirable. They admit that it would not be remunerative, and that the loss would have to be met by the State; that it would be of no benefit to the traders in other parts of England, and that the outlay could only be justified by the advantage it might be to the commerce of the country generally. It is also admitted that even with an improved system of internal waterways a large part of the traffic in goods and minerals must still be carried by the railways, that the system of trade in this country is now so carried on that the traders no longer keep stores of merchandise, but rely on quick and certain delivery of minerals and heavy goods in small consignments, conditions which the canals cannot comply with, and that, owing to this, the introduction of large trucks, which are used for the long distances traversed in the United States, has not been a success here, and this objection would apply with even greater force to barges carrying loads of Ioo tons. It is also admitted that if improved waterways were really wanted there would not have been any difficulty in this being carried out by private enterprise.

As to the estimate for carrying out the scheme, this does not include the purchase of the existing waterways, nor the cost of several items such as wharves, warehouses, terminal accommodation, Parliamentary and legal and engineering expenses. In one of the minority reports, the cost of construction and No. 2107 , vOL. 83 ] other matters included in the majority report is put at about one-third more than that given.

The evidence given also clearly shows that there is not any analogy between the conditions attaching to the waterways of this country and those on the Continent, which have been developed and improved by State aid, due to the different geographical conditions and the much longer distances over which inland transport extends.

Of the minority reports, that of Mr. Inglis, the present president of the Institution of Civil Engineers, and formerly chief engineer, and now general manager, of the Great Western Railway Company, is a very able defence of the railway companies and their dealings with canals. He points out the injustice of any State-aided effort to revive an obsolete and unsuitable mode of transit, to the detriment of the railways, which have been constructed entirely by private enterprise, and the shareholders of which receive less than three per cent. on the capital expended.

Mr. Remnant, who is a barrister, states his disagreement to the recommendations of the majority of the commissioners on the ground that these are inconclusive and left for future consideration by the proposed waterway board, and that the evidence does not warrant the conclusions arrived at on economic grounds.

Mr. Davison, who is a civil engineer, criticises the findings as to the transport and financial features, and his report contains in a brief form the substance of all the arguments that can be brought against the policy of State acquisition of the waterways. $\mathrm{He}$ is of opinion that it is extremely improbable that the traffic estimated for the proposed improved canals would be forthcoming, and that the estimate of the cost for these does not include important charges, and that no attempt is made to arrive at the ultimate cost.

\section{DR. E. PERCEVAL WRIGHT.}

WITH the death of Edward Perceval Wright one of the links connecting the old school of naturalists with the modern students of biology is severed. Wright was born in Dublin in 1834, where his father was a barrister. He early evinced a keen interest in natural history, and his enthusiasm in forwarding its study led hin to commence to publish, in 1854 , the year after his matriculation in Dublin University, a quarterly journal devoted to natural science. It was called the Natural History Review, and its publication was continued until 1866. In this journal, in the Ouarterly Journal of Microscopical Science, in the Transactions of the Linnean Society, the Journal of Botany, and in the British Association Reports, he published during the next twelve years a series of papers on the fauna of the south and west coasts of Ireland. His undergraduate studies in botany were pursued under the guidance of Prof. G. J. Allman, and as a student he came into contact with W. H. Harvey, who was then keeper of the Herbarium in Trinity College, and of whom Wright always spoke with the warmest appreciation. In 1858 Wright was appointed lecturer in zoology and director of the Natural History Museum of Trinity College. About the same time he was appointed lecturer in botany in the medical school attached to Dr. Steevens's Hospital. It is surprising to find that while he was thus engaged actively in research and teaching, he also found time to prosecute medical studies with such success that by 1865 he had begun to establish a position for himself among Dublin oculists. But he did not remain in practice long, and, 